\title{
Fatty acid profiles of Phaseolus species
}

\author{
*Adewole, E., Ojo, A., Oludoro, O. and Osasona, I. \\ Department of Chemical Sciences, Afe Babalola University Ado Ekiti, Ekiti state, Nigeria
}

\begin{abstract}
Article history:
Received: 15 August 2020

Received in revised form: 16 September 2020

Accepted: 9 November 2020

Available Online: 26

September 2021
\end{abstract}

Keywords:

Fatty acids,

Gas chromatography mass spectrophotometer,

Online Osiris server,

Chemical profiles,

Toxicity,

Drug-likeness

DOI:

https://doi.org/10.26656/fr.2017.5(5).439

\begin{abstract}
The aim of this study was to identify and profile the fatty acids present in the Phaseolus species using an online Osiris server software. Phaseolus species (pinto beans, lima beans and kidney beans) were bought in King's market, Akure, Ondo State, Nigeria and were air -dried and ground. The Association of Official Analytical Chemists protocol were used for proximate; mineral analysis was done using atomic absorption spectrophotometer; extraction of oil was done using Soxhlet apparatus and the extracts were characterized using gas chromatography mass spectrophotometer and identified compounds were screened for their chemical properties using online Osiris server. The oil extract for pinto beans revealed fatty acids in increasing order of percentage quality: Myristic acid, octadecenoic acid, stearic acid and palmitic acid. Identified fatty acids in kidney beans were in decreasing order of palmitic acid, linoleic acid, lauric acid, myristic acid and capric acid. Lima beans had highest palmitic acid and arachidic acid the lowest. However, from the results of all the Phaseolus species, linoleic acid was found only in kidney beans with quality of $11.87 \%$. The identified fatty acids showed high toxicity properties and they exhibited negative drug-likeness. The chemistry of the identified compounds all showed that they exhibited various chemical properties. In conclusion, this study had revealed the presence of fatty acids in the selected food crops and their various chemical profiles have been discovered.
\end{abstract}

\section{Introduction}

The nutritional benefits of food crops are of immense benefits to humankind and it has been well documented the various physiological functions performs in the body by consumption of various classes of food ranging from leguminous, cereals and pulses, vegetable inclusive. Among the metabolites responsible for many health benefits are the fatty acids which can be classified as essential and non-essential fatty acids. Health benefits of both essential and non-essential fatty acids and their various presences in food crops have been enumerated. Phaseolus species have been researched and found to be nutritionally rich both in protein, crude fibre, crude fat and fatty acids such as linoleic acid, stearic acid and host of others. Graham and Ranalli (1997) has reported that there are over four hundred species of Beans world-wide. The lipid content of Phaseolus vulgaris $\mathrm{L}$. is low but rich in proteins, vitamins, minerals and carbohydrate. (Graham and Ranalli, 1997; Shimelis and Rakshit, 2005; Costa et al., 2006; Anton et al., 2008; Montoya et al., 2008; Gathu and Njage, 2012).
Arvanitoyannis et al. (2007) had reported that Nutritional quality is related to the composition of the bean and that beans can be a source of proteins, vitamins (thiamine, riboflavin, niacin, vitamin B6 and folic acid), dietary fibre (14-19\%) (Particularly soluble fibre), minerals (Ca, $\mathrm{Fe}, \mathrm{Cu}, \mathrm{Zn}, \mathrm{P}, \mathrm{K}$ and $\mathrm{Mg}$ ) and unsaturated fatty acids. Furthermore, Blair et al. (2013) and Jha et al. (2015) had reported that common beans provide minerals, fibre, thiamine, folate, and phytochemicals with analgesic and neuroprotective properties.

Moreover, Phaseolus species are attracting the attention of scientists as they are considered to be a nutraceutical food as a result of a variety of phytochemicals with potent health benefits and these include unsaturated fatty acids, trypsin inhibitors and many other beneficial compounds (Guzmán -Maldonado et al., 1998). Queiroz (2005) had reported the relevance of biological activities for Phaseolus vulgaris which include fibre and phytic acid from common beans like enhancement of the bifidogenic effect, antioxidant $(\mathrm{Wu}$ et al., 2004; Heimler et al., 2005), antimutagenic 
(Cardador-Martínez, Castaño-Tostado, and Loarca-Piña 2002; Cardador-Martínez, Loarca-Piñan, and Oomahn 2002). The objective of the study was to identify the fatty acids present in the different Phaseolus species, viz. pinto beans, lima beans, and kidney bean and profile the chemical properties of the identified compounds using Osiris online server.

\section{Materials and methods}

\subsection{Sample collection}

The varieties of Phaseolus species viz. pinto beans, lima beans, and kidney bean were purchased in a local market in Akure in Ondo State, Nigeria in April 2020.

\subsection{Sample preparation}

The dried samples were powdered by using a laboratory scale grinder (Sumeet CM/L 2128945) and sifted through $300 \mu \mathrm{m}$ sieve to obtain the flour. The flour samples were sealed and packed in airtight containers for further analysis (Alves et al., 2002).

\subsection{Extraction of oil from the flour}

The conventional method of extraction involves the use of Soxhlet apparatus. This method of extraction was designed to extract lipid. Approximately, $1 \mathrm{~g}$ of moisture -free sample was wrapped in filter paper, placed in fat free thimble and then introduced in the extraction tube. Weighed, cleaned and dried receiving beaker was filled with petroleum ether and fitted into the apparatus. Water and heater were turned on to start extraction. After six siphoning, ether was allowed to evaporate and beaker disconnected before last siphoning. The extract was transferred into a clean glass dish with ether washing and the extract was concentrated using water bath. The dish was then placed in an oven at $105^{\circ} \mathrm{C}$ for $2 \mathrm{hrs}$ and cooled in a desiccator.

\subsection{Characterization of the oil extract}

The analyses of the compounds in the active extracts were run on a GC-MS system (Agilent Varian GC: 4800/3000). The fused-silica MS capillary column (30 m $0.25 \mathrm{~mm}$ ID, film thickness of $0.25 \mathrm{~mm}$ ) was directly coupled to an Agilent Varian. The oven temperature was programmed $\left(35^{\circ} \mathrm{C}\right.$ for 5 mins, then $35-300^{\circ} \mathrm{C}$ at $10^{\circ} \mathrm{C} /$ $\mathrm{min}$ ) and subsequently, held isothermal for 20 mins. The injector port; was $250^{\circ} \mathrm{C}$, the transfer line: $290^{\circ} \mathrm{C}$, spitless. The volume injected: $0.2 \mathrm{~mL}$ and the column flow rate were $1 \mathrm{~mL} / \mathrm{min}$ of $1 \mathrm{mg} / \mathrm{mL}$ solution (diluted in chloroform). The peaks of components in gas chromatography were subjected to mass-spectral analysis. The MS operate with an EI-source at $-70 \mathrm{eV}$; the solvent delay was $9 \mathrm{~min}$. Scan time $1.5 \mathrm{~s}$; acquisition rate 10 spectra/second; mass range 50-1000 amu; detector voltage $1800 \mathrm{~V}$, and Ion source temperature: $250^{\circ} \mathrm{C}$. Data were recorded in TIC mode. The software adopted to handle the mass spectra and chromatograms was Agilent chemstation software. The constituents were identified after comparing with available data in the GCMS library in the literature. The GC-MS mass spectrum data were analysed using Mnova 11.0.1 and the database of National Institute Standard and Technology (NIST) was used to interpret analysed data. Comparison of the mass spectrum of the unidentified components was carried out against the mass spectrum of already known components available in the NIST library. The name, molecular weight and peak area percentage of unknown compounds were evaluated by the software as observed from the chromatogram.

\section{Results and discussion}

Figure 1 shows the chromatogram of pinto beans and forty-seven peaks revealed the presence of various compounds at the different running time; each peak corresponds to the identified compound and its relative abundance. Table 1 shows four identified fatty acid compounds and their properties which include varying running time, molecular formula and peak numbers, the highest percentage quality was palmitic acid $(9.90 \%)$ and the least fatty acid was myristic acid $(0.12 \%)$ quality. Figure 2 shows the chromatogram of lima beans at running time of 29 mins on the $\mathrm{x}$-axis and relative abundance in $y$-axis. Table 2 shows some of the identified compounds and their properties, among is palmitic acid with highest $\%$ quality of $16.70 \%$ and Arachidic acid having $0.34 \%$ quality.

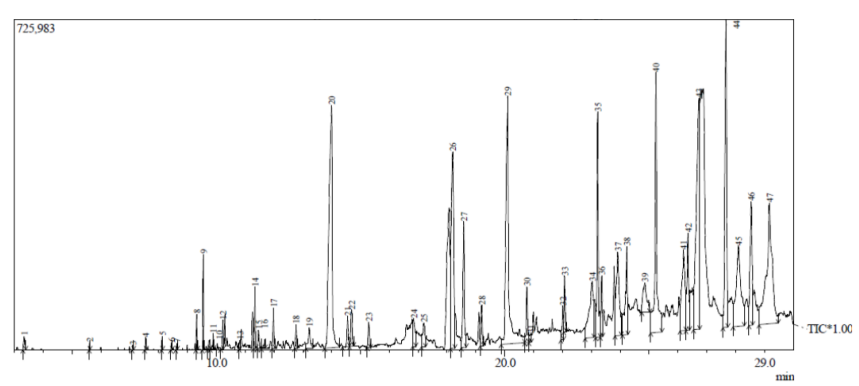

Figure 1. Chromatogram of pinto beans

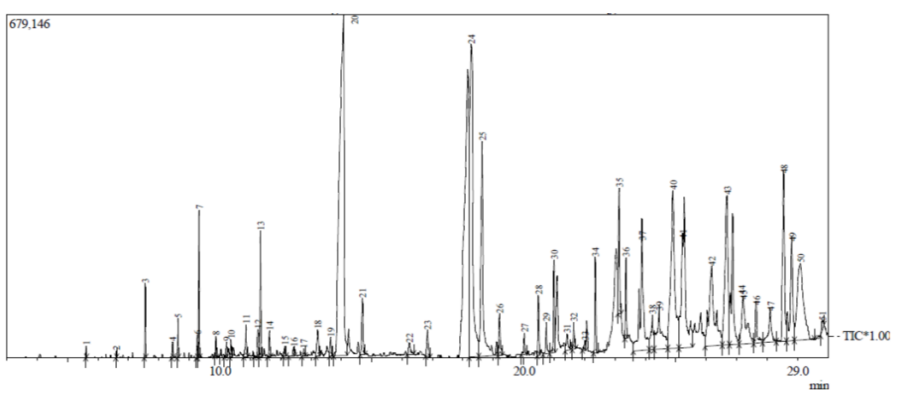

Figure 2. Chromatogram of lima beans 
Table 1. Fatty acid composition in the chromatogram of pinto beans

\begin{tabular}{cccccc}
\hline Peak No & Compound name & Retention time & \% quality & CAS & Molecular formula \\
\hline 13 & Myristic acid & 10.819 & 0.12 & CAS:544-63-8 & $\mathrm{C}_{14} \mathrm{H}_{28} \mathrm{O}_{2}$ \\
20 & Palmitic acid & 13.998 & 9.9 & $57-10-3$ & $\mathrm{C}_{16} \mathrm{H}_{32} \mathrm{O}_{2}$ \\
27 & Stearic acid & 18.578 & 2.56 & $57-11-4$ & $\mathrm{C}_{18} \mathrm{H}_{36} \mathrm{O}_{2}$ \\
36 & Octadecenoic acid & 23.355 & 1.02 & $22393-85-7$ & $\mathrm{C}_{2} 2 \mathrm{H}_{62} \mathrm{O}_{2}$ \\
\hline
\end{tabular}

Table 2. Retention time, \% quality, CAS and molecular formula of identified compounds in the chromatogram of lima beans

\begin{tabular}{cccccc}
\hline Peak No & Compound name & Retention time & \% quality & CAS & Molecular formula \\
\hline 11 & Myristic acid & 10.867 & 0.38 & $544-63-8$ & $\mathrm{C}_{14} \mathrm{H}_{28} \mathrm{O}_{2}$ \\
20 & Palmitic acid & 14.067 & 16.70 & $57-10-3$ & $\mathrm{C}_{16} \mathrm{H}_{32} \mathrm{O}_{2}$ \\
25 & Stearic acid & 18.634 & 5.39 & $57-11-4$ & $\mathrm{C}_{18} \mathrm{H}_{36} \mathrm{O}_{2}$ \\
32 & Arachidic acid & 21.633 & 0.34 & $506-30-9$ & $\mathrm{C}_{20} \mathrm{H}_{40} \mathrm{O}_{2}$ \\
\hline
\end{tabular}

Table 3. Compound names and the properties identified chromatogram of kidney

\begin{tabular}{cccccc}
\hline Peak No & Compound name & Retention time & \% quality & CAS & Molecular formula \\
\hline 2 & Capric acid & 7.208 & 0.07 & $334-48-5$ & $\mathrm{C}_{10} \mathrm{H}_{20} \mathrm{O}_{2}$ \\
6 & Lauric acid & 9.014 & 3.15 & $143-07-7$ & $\mathrm{C}_{12} \mathrm{H}_{24} \mathrm{O}_{2}$ \\
7 & Palmitic acid & 13.966 & 14.48 & $57-10-3$ & $\mathrm{C}_{16} \mathrm{H}_{32} \mathrm{O}_{2}$ \\
8 & Myristic acid & 10.881 & 1.86 & $544-63-8$ & $\mathrm{C}_{14} \mathrm{H}_{28} \mathrm{O}_{2}$ \\
14 & Linoleic acid & 18.057 & 11.87 & $60-33-3$ & $\mathrm{C}_{18} \mathrm{H}_{32} \mathrm{O}_{2}$ \\
15 & Stearic acid & 18.558 & 3.46 & $57-11-4$ & $\mathrm{C}_{18} \mathrm{H}_{36} \mathrm{O}_{2}$ \\
\hline
\end{tabular}

Table 4. Toxicological properties of the fatty acids

\begin{tabular}{lcccc}
\hline Compound names & Drug likeness & Mutagenic & Tumorigenic & Irritability \\
\hline Stearic acid & -25.216 & High & High & High \\
Myristic acid & -25.216 & High & None & High \\
Palmitic acid & -25.216 & None & High & High \\
Lauric acid & -25.216 & High & High & High \\
Linoleic acid & -25.561 & None & None & None \\
\hline
\end{tabular}

Source: Sander et al. (2015).

Table 5. Chemical properties of the identified fatty acids

\begin{tabular}{|c|c|c|c|c|c|c|c|c|c|c|c|}
\hline $\begin{array}{l}\text { Compound } \\
\text { Names }\end{array}$ & $\begin{array}{ll}\Omega & \\
I & \\
D & Z \\
0 & Z \\
0 & 0 \\
0 & 1 \\
0 & \\
\Xi & \end{array}$ & 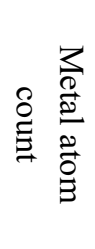 & 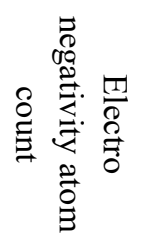 & 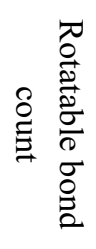 & 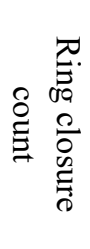 & 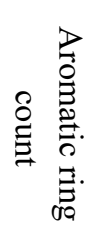 & 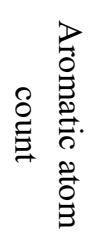 & $\begin{array}{l}\mathscr{D}_{\omega} \\
\stackrel{2}{0} \\
0 \\
\Xi \\
0 \\
\Xi \\
\Xi\end{array}$ & 尽 & 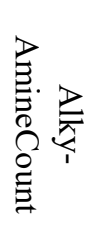 & 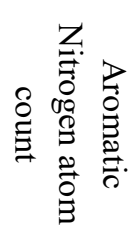 \\
\hline Stearic acid & 2 & 0 & 2 & 16 & 0 & 0 & 0 & 18 & 0 & 0 & 0 \\
\hline Myristic acid & 2 & 0 & 2 & 16 & 0 & 0 & 0 & 14 & 0 & 0 & 0 \\
\hline Palmitic acid & 2 & 0 & 2 & 14 & 0 & 0 & 0 & 16 & 0 & 0 & 0 \\
\hline Lauric acid & 2 & 0 & 2 & 10 & 0 & 0 & 0 & 12 & 0 & 0 & 0 \\
\hline Linoleic acid & 2 & 0 & 2 & 14 & 0 & 0 & 0 & 14 & 0 & 0 & 0 \\
\hline
\end{tabular}

Source: Sander et al. (2015).

Furthermore, Figure 3 shows the chromatogram of kidney beans -Phaseolus vulgaris and thirty- two peaks were identified within the running time of twenty-nine minutes and Table 3 reveals some of the identified compounds such as Palmitic acid (14.48\%), Linoleic acid (11.87\% quality).

Table 4 shows the drug-likeness and toxicological properties of the identified fatty acids in the three chromatograms, it is worthy to note that Linoleic acid exhibited no toxicity such as mutagenic, tumorigenic and irritability effect. However, all the compounds had

negative drug-likeness, which is an indication that they are not pure drugs but can be drug components.

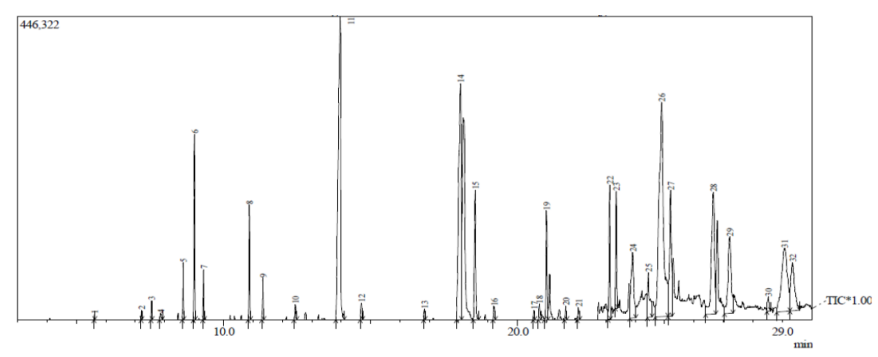

Figure 3. Chromatogram of kidney bean 
Table 5 shows the chemistry of the identified compounds such as $\mathrm{Sp}^{3}$ atom count, number of amine count, lipid number and rotatable bond count. Stearic acid had $18 \mathrm{Sp}^{3}$ atom count. It is significant to note that all the fatty acids identified had no ring closure, aromatic ring, amine, alkyl amine and aromatic Nitrogen atom counts. Table 6 shows the classification of the fatty acids into long-chain saturated and polyunsaturated fatty acids (PUFA). Only linoleic acid and Arachidic acid were PUFA while the remaining are long-chain saturated fatty acid.

Table 6. Classification of the identified fatty acids into saturated fatty acid, monounsaturated fatty acids (MUFA) contain one double bond and polyunsaturated fatty acids (PUFA) contain more than one double bond

\begin{tabular}{cc}
\hline Compound name & Class of fatty acid \\
\hline Stearic acid & saturated fatty acid \\
Myristic acid & saturated fatty acid \\
Palmitic acid & saturated fatty acid \\
Lauric acid & saturated fatty acid \\
Linoleic acid & polyunsaturated fatty acids \\
Capric acid & saturated fatty acid \\
Arachidic acid & polyunsaturated fatty acids \\
\hline
\end{tabular}

The health benefits of linoleic acid had been well discussed in learned journals. Linoleic acid is said to be a principal essential fatty acid and gained the attention of nutritionists over many years. Whelan and Fritsche (2013), had reported the various health benefits of this fatty acid to include the source of energy, that it can be esterified to form neutral and polar lipids such as phospholipids, triacylglycerols, and cholesterol esters. Moreover, PUFA identified in the kidney beans was linoleic acid and its functions in the human body have been exemplified being an essential fatty acid which cannot be synthesized in the human system; hence it is supplemented through consumption of food crops rich in it (Whelan and Fritsche, 2013). In another development, Myristic acid was identified all the Phaseolus species and the pharmacological functions of this saturated fatty acid include improvement on long-chain omega-3 fatty acids stage in plasma phospholipids and have a positive impact on cardiovascular health parameters in humans (Dabadie et al., 2005). Also, myristic acid is directly involved in post-translational protein changes and mechanisms that control important metabolic processes in the human body (Legrand and Rioux, 2015; RuizNúñez et al., 2016). Moreover, Lauric Acid has been found to possess a lot of health advantages such as in treating viral infections which includes swine flu, avian flu, fever blisters, cold sores, gonorrhoea, chlamydia.

\section{Conclusion}

The profiles of the identified fatty acids have been revealed; for pinto beans - palmitic acid: $9.90 \%$ quality, lima beans - palmitic acid: $16.70 \%$ quality, kidney beans - palmitic acid: $14.48 \%$ quality. It is worthy to mention that the fatty acids identified all showed negative values for drug-likeness such as stearic acid (-25.216) and linoleic acid (-25.561) which is an indication that they are not drugs and also their toxicities have been evaluated. It is significant to note that the identified fatty acids all have the same electronegativity atom count which means that they possess the power to attract bonding pair of electrons and their $\mathrm{Sp}^{3}$ varied.

\section{References}

Anton, A.A., Ross, K.A., Beta, T., Fulcher, R.G. and Arntfield, S.D. (2008). Effect of pre- dehulling treatments on some nutritional and physical properties of navy and pinto beans (Phaselus vulgaris L.). Food Science and Technology, 41(5), 771- 778. https://doi.org/10.1016/j.lwt.2007.05.014

Alves, R.M., Grossmann, M.V., Ferrero, C., Zaritzky, N.E., Martino, M.N. and Sierakoski, M.R. (2002). Chemical and Functional Characterization of Products Obtained from Yam Tubers, Starch Stärke, 54(10), 476-481. https:// doi.org/10.1002/1521-379X(200210) 54:10<476::AID-STAR476>3.0.CO;2-6

Arvanitoyannis, I.S., Mavromatis, A., Rodiatis, A. and Goulas, C. (2007). Physicochemical and sensory analysis of dry bean landraces in conjunction with multivariate analysis: an exploratory approach. International Journal of Food Science and Technology, 42(7), 819-826. https://doi.org/10.1111/ j.1365-2621.2007.01289.x

Blair, M.W., Izquierdo, P., Astudillo, C. and Grusak, M.A. (2013). A legume biofortification quandary: variability and genetic control of seed coat micronutrient accumulation in common beans. Frontiers in Plant Science, 4, e00275. https:// doi.org/10.3389/fpls.2013.00275

Costa, E.G.A., Monici, K.S.Q., Reis, S.M.P.M. and Oliveira, A.C. (2006). Chemical composition, dietary fiber and resistant starch contents of raw and cooked pea, common bean, chickpea and lentil legumes. Food Chemistry, 94(3), 327-330. https:// doi.org/10.1016/j.foodchem.2004.11.020

Cardador-Martínez, A., Loarca-Piñan, G. and Oomahn, B.D. (2002). Antioxidant activity in common beans (Phaseolus vulgaris L.). Journal of Agricultural and Food Chemistry, 50, 6975-6980. https:// doi.org/10.1021/jf020296n 
Cardador-Martínez, A., Castaño-Tostado, E. and LoarcaPiña, G. (2002). Antimutagenic activity of natural phenolic compounds in the common bean (Phaseolus vulgaris) against aflatoxin B1. Food Additives and Contaminants, 19(1), 62-69. https:// doi.org/10.1080/02652030110062110

Dabadie, H., Peuchant, E., Bernard, M., LeRuyet, P. and Mendy, F. (2005). Moderate intake of myristic acid in sn-2 position has beneficial lipidic effects and enhances DHA of cholesteryl esters in an interventional study. Journal of Nutritional Biochemistry, 16(6), 375-82. https://doi.org/10.1016/ j.jnutbio.2005.01.010

Gathu, W.E. and Njage, P.M.K. (2012). Physical characterization of new advanced drought tolerant common bean (Phaseolus vulgaris) lines for canning quality. American Journal of Food Technology, 7(2), 22-28. https://doi.org/10.3923/ajft.2012.22.28

Graham, P.H. and Ranalli, P. (1997). Common bean. Field Crops Research, 53(1-3), 131-146. https:// doi.org/10.1016/S0378-4290(97)00112-3

Guzmán-Maldonado, S.H. and Paredes-López, O. (1998). Functional products of plants indigeneous of Latin America: amaranth, quinoa, common beans and botanicals. In Mazza, G. (Ed.) Functional Foods. Biochemical and Processing Aspects, p. 293-328. Lancaster: Technomic Publishing Co. Inc.

Heimler, D., Vignolini, P., Dini, M.G. and Romani A. (2005). Rapid tests to assess the antioxidant activity of Phaseolus vulgaris L. dry beans. Journal of Agricultural and Food Chemistry, 53, 3053-3056. https://doi.org/10.1021/jf049001r

Jha, A.B., Ashokkumar, K., Diapari, M., Ambrose, S.J., Zhang, H., Tar'an, B., Bett, K.E., Vandenberg, A., Warkentin, T.D. and Purves, R.W. (2015). Genetic diversity of folate profiles in seeds of common bean, lentil, chickpea and pea. Journal of Food Composition and Analysis, 42, 134-140. https:// doi.org/10.1016/j.jfca.2015.03.006

Legrand, P. and Rioux, V. (2015). Specific roles of saturated fatty acids: Beyond epidemiological data. European Journal of Lipid Science and Technology, 117(10), 1489-1499. https://doi.org/10.1002/ ejlt.201400514

Montoya, C.A., Leterme, P., Victoria, N.F., Toro, O., Souffrant, W.B., Beebe, S. and Lalles, J.P. (2008). Susceptibility of phaseolin to in vitro proteolysis is highly variable across common bean varieties (Phaseolus vulgaris). Journal Agricultural of Food Chemistry, 56(6), 2183-2191. https:// doi.org/10.1021/jf072576e

Queiroz-Monici, K.S., Costa, G.E.A., da Silva, N, Reis,
S.M.P.M. and de Oliveira, A.C. (2005). Bifidogenic effect of dietary fiber and resistant starch from leguminous on the intestinal microbiota of rats. Nutrition, 21(5), 602-609. https://doi.org/10.1016/ j.nut.2004.09.019

Ruiz-Núñez, B., Dijck-Brouwer, D.A.J. and Muskiet, F.A.J. (2016). The relation of saturated fatty acids with low-grade inflammation and cardiovascular disease. Journal of Nutritional Biochemistry, 36, 120. https://doi.org/10.1016/j.jnutbio.2015.12.007

Sander, T., Freyss, J., von Korff, M. and Rufener, C. (2015). Osiris Online Server, Data Warrior. An Open -Source Program for Chemistry Aware Data Visualization and Analysis. Journal of Chemical Information and Modeling, 55, 460-473. https:// doi.org/10.1021/ci500588j

Shimelis, E.A. and Rakshit, S.K. (2005). Proximate composition and physico-chemical properties of improved dry bean (Phaseolus vulgaris L.) varieties grown in Ethiopia. LWT-Food Science and Technology, 38(4), 331-338. https://doi.org/10.1016/ j.lwt.2004.07.002

Whelan, J. and Fritsche, K. (2013). Linoleic Acid. Advances in Nutrition, 4(3), 311-312. https:// doi.org/10.3945/an.113.003772

Wu, X.L., Beecher, G.R., Holden, J.M., Haytowitz, D.B., Gebhardt, S.E. and Prior, R.L. (2004). Lipophilic and hydrophilic antioxidant capacities of common foods in the United States. Journal of Agricultural and Food Chemistry, 52, 4026-4037. https:// doi.org/10.1021/jf049696w 